\title{
PENGELOLAAN TAMAN PENITIPAN ANAK DI TK FKIP UNIVERSITAS RIAU
}

\author{
Daviq Chairilsyah ${ }^{1}$, , \\ 1 Universitas Riau
}

\begin{abstract}
Abstrak
Penelitian ini untuk mengetahui bagaimana gambaran pengelolaan TPA di TK FKIP UR adapun subjek penelitian dalam penelitian ini adalah Taman Penitipan Anak di FKIP UR dengan jumlah indikator yang akan di teliti sebanyak 8 indikator dan 22 sub indikator manajemen pengelolaan TPA. Metode yang digunakan yaitu metode deskriptif kuantitatif untuk mengetahui gambaran pengelolaan TPA. Teknik pengumpulan data yang digunakan yaitu menggunakan lembar observasi. Berdasarkan hasil analisis data diperoleh hasil persentase dari 8 indikator yaitu: Pengaturan fisik TPA FKIP UR sebesar (75\%) maka TPA FKIP UR sudah dikatakan baik (B). Mainan dan Peralatan TPA FKIP UR sebesar (70\%) maka TPA FKIP UR sudah dikatakan baik (B). Rasio pengasuh anak TPA FKIP UR sebesar $(62,5 \%)$ maka TPA FKIP UR sudah dikatakan baik (B). Kegiatan sehari-hari TPA FKIP UR sebesar (100\%) maka TPA FKIP UR sudah dikatakan sangat baik (SB). Kualifikasi pengasuh TPA FKIP UR sebesar (75\%) maka TPA FKIP UR sudah dikatakan baik (B). Interaksi orang dewasa TPA FKIP UR sebesar $(83,333 \%)$ maka TPA FKIP UR sudah dikatakan sangat baik (SB). Hubungan dengan orang tua TPA FKIP UR sebesar (100\%) maka TPA FKIP UR sudah dikatakan sangat baik (SB). Perizinan dan akreditasi TPA FKIP UR adalah (75\%) maka TPA FKIP UR sudah dikatakan baik (B). Secara umum manajemen pengelolaan TPA FKIP UR sudah dapat dikategorikan Baik.
\end{abstract}

\author{
Keywords: \\ Pengelolaan, Taman \\ Penitipan Anak, Anak \\ Usia Dini.
}

\section{PENDAHULUAN}

Pendidikan nasional sebagaimana yang diamanatkan dalam Undang-Undang Nomor 20 tahun 2003, dikenal dalam tiga jalur yaitu jalur pendidikan informal, jalur pendidikan formal dan jalur pendidikan nonformal. Dimana antara jalur-jalur tersebut saling melengkapi dalam mengembangkan sumber daya manusia. Pendidikan nonformal sebagaimana tercantum dalam Undang-Undang Nomor 20 tahun 2003 pasal 26 ayat 3, diuraikan bahwa pendidikan nonformal meliputi pendidikan kecakapan hidup, pendidikan anak usia dini, pendidikan kepemudaan, pendidikan pemberdayaan perempuan, pendidikan keaksaraan, pendidikan keterampilan dan pelatihan kerja, pendidikan kesetaraan, serta pendidikan lain yang ditujukan untuk mengembangkan kemampuan peserta didik. Salah satu kebijakan pemerintah di sektor pendidikan yang mendukung pendidikan sepanjang hayat adalah diakuinya pendidikan anak usia dini (PAUD) (Heorniasih, 2017). Salah satu jalur terselenggaranya PAUD adalah jalur pendidikan nonformal. PAUD jalur nonformal adalah pendidikan yang melaksanakan program pembelajaran secara fleksibel sebagai upaya pembinaan dan pengembangan anak sejak lahir sampai 6 tahun yang dilakukan melalui Taman Penitipan Anak (TPA), kelompok bermain dan bentuk lain yang sederajat. Taman Penitipan Anak (TPA) merupakan bentuk layanan Pendidikan Anak Usia Dini (PAUD) Non-Formal yang terus berkembang jumlahnya. Taman Penitipan Anak telah dikembangkan oleh Departemen Sosial sejak tahun 1963 sebagai upaya untuk memenuhi kebutuhan pengasuh, pembinaan, bimbingan, sosial anak balita selama anak tidak bersama orangtua. Dengan dikeluarkannya Undang-undang No. 20 Tahun 2003 tentang Sistem Pendidikan Nasional (Sisdiknas), maka pengembangan pendidikan usia dini mulai dilakukan dengan baik. Peran pemerintah secara langsung maupun peran pemerintah untuk mendorong pengembangan PAUD yang lebih berkualitas. Dalam hal ini UU No, 20 Tahun 2003 tentang Sisidiknas menyatakan bahwa yang dimaksud pendidikan usia dini adalah suatu upaya pembinaan yang ditujukan kepada anak sejak lahir sampai dengan usia enam tahun yang dilakukan melalui pemberian rangsangan 
pendidikan untuk membantu pertumbuhan dan perkembangan jasmani dan rohani agar anak memiliki kesiapan dalam memasuki pendidikan lebih lanjut. Layanan TPA merupakan salah satu bentuk Pendidikan Anak Usia Dini (PAUD) nonformal yang diarahkan pada kegiatan pengasuhan anak bagi orang tua yang mempunyai kesibukan kerja, sehingga memerlukan sebuah layanan pengasuh anak yang selain berfungsi untuk menjag aanak-anak mereka juga memberikan pendidikan yang sesuai dengan usia anakanak mereka.

Walau lembaga penitipan anak semakin tersedia, akan tetapi pada umumnya pengelolaannya hanya sebatas pada kesejahteraan anak, dan belum menyentuh pendidikan secara menyeluruh. Pelayanan pendidikan yang menyeluruh bagi anak merupakan hal yang sangat penting untuk dilakukan. Dengan pelayanan pendidikan yang menyeluruh anak akan tumbuh dan berkembang secara optimal.

Pengelolaan pendidikan bukanlah mengelola sebuah tempat usaha barang, melainkan mengelola sumber daya manusia dimasa mendatang. Suatu bencana besar ketika manusia mengelola pendidikan hanya dilihat dari kacamata pribadi, orang yang demikian ini termasuk melemahkan generasi mendatang. Begitu pula bagi orang yang mengembangkan pendidikan hanya mengandalkan kekuasaan semata. Untuk itulah dibutuhkan formula yang tepat dalam mengatur segala permasalahan manajemen pendidikan anak usia dini.

Menurut Permendikbud No 137 Tahun 2014 tentang Standar Nasional Pendidikan Anak Usia Dini selanjutnya disebut standar PAUD adalah kriteria tentang pengelolaan dan penyelenggaraan PAUD diseluruh wilayah hukum Negara Kesatuan Republik Indonesia. Standar Pengelolaan adalah kriteria tentang perencanaan, pelaksanaan, dan pengawasan kegiatan pendidikan pada tingkat satuan atau program PAUD. Manajemen yang efektif dan efisien pada Taman Penitipan Anak (TPA) sangat diperlukan agar nantinya kebutuhan anak untuk mendapatkan pelayanan pendidikan tetap terlaksana sesuai dengan tumbuh dan kembang anak, meskipun orang tua sibuk bekerja (Fitrianti, 2015). Manajemen yang baik akan menjadi tolak ukur keberhasilan lembaga pendidikan dalam memberikan layanan pendidikan yang berkualitas dan profesional. Manajemen yang perencanaannya teratur akan sangat berpengaruh terhadap keberhasilan pelayanan Pendidikan Anak Usia Dini (PAUD).

Munculnya lembaga-lembaga pendidikan plus fullday merupakan indikator betapa semakin dibutuhkannya Taman pendidikan anak. Kehadiran Taman Pendidikan Anak (TPA) sebagai lembaga pelayanan sosial pengganti saat ini. Untuk memenuhi kebutuhan yang semakin luas dan menjawab tantangan permasalahan yang lebih kompleks, maka ke depannya TPA harus merubah paradigma pelayanan. TPA harus tampil tidak hanya sebagai pengganti peran orang tua sementara waktu, tetapi harus mampu berfungsi sebagai lembaga pengembangan kapasitas anak sejak usia dini. Pelayanan TPA saat ini harus holistik, integral dan tidak bersandar pada fungsi perawatan dan pengasuhan saja (care dan parenting service). Fungsi perawatan dan pengasuhan termasuk fungsi-fungsi TPA yang lain, seperti fungsi riset, pendidikan dan pelatihan.

Berkaitan dengan harapan-harapan di atas baik berasal Departemen Sosial maupun lembaga, di dalam proses pengasuhan sementara masih terdapat harapan atau keinginan dari para orang tua yang menitipkan anaknya di Tempat Penitipan Anak. Para orang tua berharap lembaga memberi suasana lingkungan kekeluargaan dimana aspek kelekatan antara pengasuh dengan anak yang diasuh menjadi unsur utama di dalam proses asuhan, agar supaya anak bisa nyaman dan merasa betah di TPA yang ditempatkan orang tua anak.

Dari pengamatan penulis, (1) masih ada beberapa di TPA pengasuhnya tidak punya pengetahuan tentang PAUD atau TPA. (2) masih ada ruangan TPA yang belum layak (3) kurangnya alat permainan anak di dalam ruangan, (4) masih ada TPA yang belum mengurus surat izin ke dinas pendidikan,(5) masih banyak TPA kekurangan guru di dalam ruangan.

Dari paparan latar belakang di atas, penulis tertarik untuk melakukan penelitian tentang Gambaran Pengelolaan TPA di TK FKIP UR dengan jumlah 8 indikator yang akan diteliti oleh peneliti.

\section{METODE PENELITIAN}

Jenis penelitian ini dilakukan dengan metode deskriptif dengan pendekatan kuantitatif. Pendekatan ini menganalisis informasi tentang fenomena utama yang dieksplorasi dalam penelitian, partisipan penelitian, dan lokasi penelitian. Pendekatan ini digunakan karena "Lebih mudah apabila berhadapan dengan kenyataan, dan menyajikan secara langsung hakikat hubungan antara peneliti dengan responden, lebih peka dan lebih dapat menyesuaikan diri dengan banyak penajaman pengaruh bersama terhadap polapola nilai yang dihadapi" (Moleong, 2004:5). "Melalui pendekatan kualitatif ini tujuan penelitian ditulis dengan istilah-istilah "teknis" penelitian yang bersumber dari bahasa penelitian kualitatif" (Schwandt, 2007 dalam Cresswell, 2013:167). Pendekatan ini tepat untuk memperoleh bagaimana gambaran pengelolaan TPA di TK FKIP UR dengan jumlah 8 indikator yang akan diteliti. Teknik analisis 
data yang diperoleh dianalisis untuk mengetahui hasil statistik deskriptif yang menggambarkan pengelolaan TPA di TK FKIP UR. Selanjutnya, untuk mengetahui gambaran pengelolaan TPA (baik, sedang, rendah) digunakan rumus:

Ket: $\mathrm{P}=$ Persentase

$\mathrm{F}=$ Frekuensi

$\mathrm{N}=$ Jumlah subjek

$$
P=\frac{F}{N} X 100 \%
$$

Data yang diperoleh lalu ditabulasi untuk mengetahui gambaran pengelolaan TPA sehingga dapat diketahui bagaimana gambaran pengelolaan TPA di TK FKIP UR saat ini dengan jumlah 8 indikator tersedia pada Tabel 1 berikut.

Tabel 1. Gamabaran sementara pengelolaan TPA di TK FKIP UR

\begin{tabular}{|c|c|}
\hline Indikator & Sub indikator \\
\hline Pengaturan fisik & $\begin{array}{l}\text { Lingkungan dalam ruangan sekolah. } \\
\text { a. tampak baik dan tidak tampak sesak saat anak- anak } \\
\text { hadir } \\
\text { b. Ruangan bermain berpagar } \\
\text { c. luar ruangan tersedia }\end{array}$ \\
\hline $\begin{array}{l}\text { Mainan dan } \\
\text { peralatan }\end{array}$ & $\begin{array}{l}\text { N Peralatan permainan dalam ruangan } \\
\text { a. Mainan dan peralatan sesuai untuk bayi dan balita } \\
\text { b. Mainan di tempatkan di rak- rak dan boks yang } \\
\text { mudah di jangkau anak } \\
\text { c. Tersedianya kursi tinggi, kursi bayi, meja dan kursi } \\
\text { berukuran kecil }\end{array}$ \\
\hline & $\begin{array}{l}\text { Peralatan permainan di luar ruangan } \\
\text { a. Adanya ayunan } \\
\text { b. Seluncuran, kuda kuda kecil dan kotak pasir }\end{array}$ \\
\hline Rasio guru & $\begin{array}{l}\text { a. Usia } 0-2 \text { tahun: rasio guru dan anak } 1: 3 \\
\text { b. Usia 2-4 tahun: rasio guru dan anak } 1: 6\end{array}$ \\
\hline Kegiatan sehari-hari & $\begin{array}{l}\text { a. Adanya waktu bermain aktif untuk anak-anak dan } \\
\text { permainan santai. } \\
\text { b. Adanya tidur siang untuk anak-anak } \\
\text { c. Adanya jadwal makanan ringan dan makan siang } \\
\text { untuk anak } \\
\text { d. Anak-anak tidak pernah ditinggalkan tanpa } \\
\text { pengawasan guru } \\
\text { e. Pelaksanaan program kerja yang sudah } \\
\text { direncanakan di TPA }\end{array}$ \\
\hline $\begin{array}{lr}\text { Interaksi } & \text { orang } \\
\text { dewasa } & \text { dengan } \\
\text { anak-anak } & \end{array}$ & $\begin{array}{l}\text { Terpenuhinya hak dan kebutuhan anak serta } \\
\text { kesinambungan TPA } \\
\text { a. Menanggapi penderitaan bayi dan balita } \\
\text { b. Bercerita dengan anak } \\
\text { c. Bernyanyi bersama anak-anak }\end{array}$ \\
\hline
\end{tabular}

Kualifikasi pengasuh

a. Apakah ada pengasuh mengikuti pelatihan perkembangan anak?

b. Apakah ada pengasuh mengikuti pelatihan kesehatan untuk anak?

Hubungan dengan a. Adanya komunikasi pengasuh dengan orang tua.

orang tua $\quad$ b. Pengasuh menceritakan perkembangan anak kepada 


\begin{tabular}{|c|c|c|}
\hline & & $\begin{array}{l}\text { orang tua. } \\
\text { c. Orang tua diperbolehkan kapan saja bertanya kepada } \\
\text { pengasuh. }\end{array}$ \\
\hline $\begin{array}{l}\text { Perizinan } \\
\text { akreditasi }\end{array}$ & atau & $\begin{array}{l}\text { Sudah adanya perizinan dari dinas pendidikan untuk } \\
\text { pendirian lembaga TPA. }\end{array}$ \\
\hline
\end{tabular}

\section{HASIL DAN PEMBAHASAN}

Analisis data dilakukan dengan cara observasi untuk mengetahui hasil gambaran pengelolaan TPA di TK FKIP UR dengan mengetahui tentang Pengaturan fisik TPA. 1. Mainan dan permainan anak, 2. Rasio guru, 3. Kegiatan sehari-hari anak, 4. Interaksi orang dewasa dengan anak-anak, 5. Kualifikasi pengasuh, 6. Hubungan dengan orang tua, dan 7. Perizinan atau akreditasi. Gambaran tentang Pengelolaan TK FKIP UR dapat dilihat pada Tabel 2 dibawah ini :

Tabel 2. Gambaran Pengelolaan TK FKIP UR

\begin{tabular}{lcccc}
\hline Pengaturan fisik TPA FKIP UR & Frekuensi & $\begin{array}{l}\text { Jumlah } \\
\text { skor }\end{array}$ & Persentase & Kategori \\
$\begin{array}{l}\text { Ruangan TPA yang terlihat rapi. } \\
\text { Keadaan ruangan bermain anak }\end{array}$ & 3 & 4 & 75 & $\mathrm{~B}$ \\
$\begin{array}{l}\text { yang nyaman dan aman. } \\
\text { JUMLAH }\end{array}$ & 6 & 4 & 75 & $\mathrm{~B}$ \\
\hline
\end{tabular}

Berdasarkan Tabel 2 maka dapat dilihat bahwa pengaturan fisik dalam indikator keadaan ruangan TPA dengan baik dan rapi (75\%) maka TPA FKIP UNRI sudah dikatakan baik (B) dan indikator dengan keadaan ruangan bermain anak yang nyaman dan aman (75\%) maka TPA FKIP UNRI sudah dikatakan baik (B). Secara keseluruhan pengaturan fisik TPA FKIP UR adalah (75\%) maka TPA FKIP UR sudah dikatakan baik (B). Gambaran tentang pengelolaan TPA FKIP UR dapat dilihat pada tabel 3 berikut.

Tabel 3 Gambaran Pengelolaan TPA FKIP UR

\begin{tabular}{|c|c|c|c|c|}
\hline $\begin{array}{l}\text { Mainan dan Peralatan TPA } \\
\text { FKIP UR }\end{array}$ & Frekuensi & $\begin{array}{l}\text { Jumlah } \\
\text { skor }\end{array}$ & Persentase & Kategori \\
\hline Kursi kecil untuk anak & 2 & 4 & 50 & $\mathrm{C}$ \\
\hline Meja makan untuk anak & 2 & 4 & 50 & $\mathrm{C}$ \\
\hline $\begin{array}{l}\text { Tempat penyimpanan mainan } \\
\text { anak seperti boks }\end{array}$ & 3 & 4 & 75 & $\mathrm{~B}$ \\
\hline Kasur tidur anak & 3 & 4 & 75 & $\mathrm{~B}$ \\
\hline $\begin{array}{l}\text { Mainan luar ruangan untuk } \\
\text { anak }\end{array}$ & 4 & 4 & 100 & SB \\
\hline JUMLAH & 14 & 20 & 70 & $\mathrm{~B}$ \\
\hline
\end{tabular}

Berdasarkan tabel 3 maka dapat dilihat bahwa Mainan dan Peralatan TPA FKIP UR dalam indikator Kursi kecil untuk anak (50\%) maka TPA FKIP UR sudah dikatakan cukup (C). Idikator Meja makan untuk anak (50\%) maka TPA FKIP UR sudah dikatakan cukup (C). Indikator Tempat penyimpanan mainan anak seperti boks (75\%) maka TPA FKIP UNRI sudah dikatakan baik (B). Indikator Kasur tidur anak (75\%) maka TPA FKIP UNRI sudah dikatakan baik (B). Indikator Mainan luar ruangan untuk anak (100\%) maka TPA FKIP UNRI sudah dikatakan sangat baik (SB). Secara keseluruhan Mainan dan Peralatan TPA FKIP UR adalah (70\%) maka TPA FKIP UR sudah dikatakan baik (B). Selanjutnya yaitu tentang gambaran pengelolaan TPA FKIP UR dapat dilihat pada Tabel 4 berikut:

Tabel 4 Gambaran Pengelolaan TPA FKIP UR

\begin{tabular}{lcccc}
\hline Rasio Pengasuh Anak & Frekuensi & $\begin{array}{l}\text { Jumlah } \\
\text { skor }\end{array}$ & Persentase & Kategori \\
\hline $\begin{array}{l}\text { Dari usia 0-2 tahun, 1 pengasuh } \\
\text { fokus terhadap 3 orang anak } \\
\text { saja }\end{array}$ & 4 & 4 & 100 & SB \\
\hline
\end{tabular}




\begin{tabular}{lllll}
\hline $\begin{array}{l}\text { Dari usia 2-4 tahun, 1 pengasuh } \\
\text { fokus terhadap 6 orang anak } \\
\text { saja }\end{array}$ & 1 & 4 & 25 & $\mathrm{~K}$ \\
JUMLAH & 5 & 8 & 62,5 & $\mathrm{~B}$ \\
\hline
\end{tabular}

Berdasarkan tabel 4 maka dapat dilihat bahwa indikator rasio pengasuh anak TPA FKIP UR dalam sub indikator dari usia 0-2 tahun 1 pengasuh fokus terhadap 3 orang anak saja (100\%) maka TPA FKIP UR sudah dikatakan sangat baik (SB). Sub indikator dari usia 2-4 tahun 1 pengasuh fokus terhadap 6 orang anak (25\%) maka TPA FKIP UR masih dikatakan kurang (K). Secara keseluruhan Rasio pengasuh anak TPA FKIP UR adalah (62,5\%) maka TPA FKIP UR sudah dikatakan baik (B). Gambaran Pengelolaan TPA FKIP UR dapat dilihat pada Tabel 5 dibawah ini.

Tabel 5 Gambaran Pengelolaan TPA FKIP UR

\begin{tabular}{lcccc}
\hline Kegiatan sehari-hari & Frekuensi & $\begin{array}{l}\text { Jumlah } \\
\text { skor }\end{array}$ & Persentase & Kategori \\
$\begin{array}{l}\text { Bagaimana kegiatan tidur siang } \\
\text { anak }\end{array}$ & 4 & 4 & 100 & SB \\
$\begin{array}{l}\text { Bagaimanakah kegiatan makan } \\
\text { snak dan makan siang untuk }\end{array}$ & 4 & 4 & 100 & SB \\
anak yang bernyanyi dan & 4 & 4 & 100 & SB \\
Guru yang \\
bercerita di depan anak yang \\
menggunakan media audio \\
visual
\end{tabular}

Berdasarkan tabel 5 maka dapat dilihat bahwa indikator kegiatan sehari-hari TPA FKIP UR dalam sub indikator Bagaimana kegiatan tidur siang anak (100\%) maka TPA FKIP UR sudah dikatakan sangat baik (SB). Sub indikator Bagaimanakah kegiatan makan snak dan makan siang untuk anak (100\%) maka TPA FKIP UR sudah dikatakan sangat baik (SB). Sub indikator Guru yang bernyanyi dan bercerita di depan anak yang menggunakan media audio visual (100\%) maka TPA FKIP UR sudah dikatakan sangat baik (SB). Secara keseluruhan kegiatan sehari-hari TPA FKIP UR adalah (100\%) maka TPA FKIP UR sudah dikatakan sangat baik (SB). Gambaran Pengelolaan TPA FKIP UR dapat dilihat pada tabel 6

Tabel 6 Gambaran Pengelolaan TPA FKIP UR

\begin{tabular}{ccccc}
\hline Kualifikasi Pengasuh & Frekuensi & $\begin{array}{l}\text { Jumlah } \\
\text { skor }\end{array}$ & Persentase & Kategori \\
\hline $\begin{array}{l}\text { Pengasuh mengikuti pelatihan } \\
\text { tentang TPA dan perkembangan }\end{array}$ & 3 & 4 & 75 & $\mathrm{~B}$ \\
$\begin{array}{l}\text { anak } \\
\begin{array}{l}\text { Pengasuh mengikuti pelatihan } \\
\text { tentang kesehatan anak }\end{array}\end{array}$ & 3 & 4 & 75 & $\mathrm{~B}$ \\
$\quad$ JUMLAH & 6 & 8 & 75 & $\mathrm{~B}$ \\
\hline
\end{tabular}

Berdasarkan tabel 6 maka dapat dilihat bahwa indikator kualifikasi pengasuh TPA FKIP UR dalam sub indikator Pengasuh mengikuti pelatihan tentang TPA dan perkembangan anak (75\%) maka TPA FKIP UR sudah dikatakan baik (B). Sub indikator Pengasuh mengikuti pelatihan tentang kesehatan anak (75\%) maka TPA FKIP UR sudah dikatakan baik (B). Secara keseluruhan kualifikasi pengasuh TPA FKIP UR adalah (75\%) maka TPA FKIP UR sudah dikatakan baik (B). Gambaran Pengelolaan TPA FKIP UR tentang interaksi orang dewasa dapt dilihat pada Tabel 7 berikut.

Tabel 7 Gambaran Pengelolaan TPA FKIP UR

\begin{tabular}{cccccc}
\hline \multicolumn{2}{c}{ Interaksi orang dewasa } & Frekuensi & $\begin{array}{l}\text { Jumlah } \\
\text { skor }\end{array}$ & Persentase & Kategori \\
\hline $\begin{array}{l}\text { Bagaimanakah cara pengasuh } \\
\text { menanggapi penderitaan bayi }\end{array}$ & 4 & 4 & 100 & SB \\
\hline
\end{tabular}




\begin{tabular}{lllll}
\hline atau balita & 3 & 4 & 75 & B \\
$\begin{array}{l}\text { Pengasuh mengajak anak bayi } \\
\text { atau balita bercerita }\end{array}$ & 3 & 4 & 75 & B \\
$\begin{array}{l}\text { Pengasuh mengajak bayi dan } \\
\text { balita bernyanyi } \\
\text { JUMLAH }\end{array}$ & 10 & 12 & 83,333 & SB \\
\hline
\end{tabular}

Berdasarkan tabel 7 maka dapat dilihat bahwa indikator interaksi orang dewasa TPA FKIP UR dalam sub indikator Bagaimanakah cara pengasuh menanggapi penderitaan bayi atau balita (100\%) maka TPA FKIP UR sudah dikatakan sangat baik (SB). Sub indikator Pengasuh mengajak anak bayi atau balita bercerita (75\%) maka TPA FKIP UR sudah dikatakan baik (B). Sub indikator Pengasuh mengajak bayi dan balita bernyanyi (75\%) maka TPA FKIP UR sudah dikatakan baik (B). Secara keseluruhan indikator interaksi orang dewasa TPA FKIP UR adalah $(83,333 \%)$ maka TPA FKIP UR sudah dikatakan sangat baik (SB). Gambaran Pengelolaan TPA FKIPUR tentang hubungan dengan orang dewasa dapat dilihat pada Tabel 8 dibawah ini.

Tabel 8 Gambaran Pengelolaan TPA FKIP UR

\begin{tabular}{lccccc}
\hline $\begin{array}{l}\text { Hubungan dengan orang } \\
\text { dewasa }\end{array}$ & Frekuensi & $\begin{array}{l}\text { Jumlah } \\
\text { skor }\end{array}$ & Persentase & Kategori \\
\hline $\begin{array}{l}\text { Bagaimanakah pengasuh } \\
\text { menceritakan perkembangan }\end{array}$ & 4 & 4 & 100 & SB \\
bayi dan balita semasa di TPA & & & & \\
Ketika orang tua bertanya & 4 & 4 & 100 & SB \\
adakah pengasuh menjelaskan & & & & \\
secara ditail kepada orang tua & & & & \\
tentang anak & 4 & 4 & 100 & SB \\
Orang tua diperbolehkan \\
bertanya kapan saja kepada \\
pengasuh \\
JUMLAH
\end{tabular}

Berdasarkan tabel 4.7 maka dapat dilihat bahwa indikator hubungan dengan orang tua TPA FKIP UR dalam sub indikator Bagaimanakah pengasuh menceritakan perkembangan bayi dan balita semasa di TPA (100\%) maka TPA FKIP UR sudah dikatakan sangat baik (SB). Sub indikator Ketika orang tua bertanya adakah pengasuh menjelaskan secara ditail kepada orang tua tentang anak (100\%) maka TPA FKIP UR sudah dikatakan sangat baik (SB). Sub indikator Orang tua diperbolehkan bertanya kapan saja kepada pengasuh (100\%) maka TPA FKIP UR sudah dikatakan sangat baik (SB). Secara keseluruhan indikator hubungan dengan orang tua TPA FKIP UR adalah (100\%) maka TPA FKIP UR sudah dikatakan sangat baik (SB). Gambaran Pengelolaan TPA FKIP UR tentang Perizinan dan Akreditasi dapat dilihat pada Tabel 9 dibawah ini.

Tabel 9 Gambaran Pengelolaan TPA FKIP UR

$\begin{array}{llccccr}\text { Perizinan dan Akreditasi } & \text { Frekuensi } & \begin{array}{l}\text { Jumlah } \\ \text { skor }\end{array} & \text { Persentase } & \text { Kategori } \\ \begin{array}{l}\text { TPA sudah memiliki izin dari } \\ \text { dinas }\end{array} & 3 & 4 & 75 & \text { SB } \\ \begin{array}{l}\text { Sekolah sudah } \\ \begin{array}{l}\text { akreditasi memiliki } \\ \quad \text { JUMLAH }\end{array}\end{array} & 3 & 4 & 75 & \text { SB } \\ \end{array}$

Berdasarkan Tabel 9 maka dapat dilihat bahwa indikator perizinan dan akreditasi TPA FKIP UR dalam sub indikator TPA sudah memiliki izin dari dinas (75\%) maka TPA FKIP UR sudah dikatakan baik (B). sub indikator Sekolah sudah memiliki akreditasi (75\%) maka TPA FKIP UNRI sudah dikatakan baik (B). Secara keseluruhan perizinan dan akreditasi TPA FKIP UR adalah (75\%) maka TPA FKIP UR sudah dikatakan baik (B).

\section{KESIMPULAN}


Berdasarkan hasil penelitian dan pembahasan pada bagian terdahulu, maka dapat ditarik kesimpulan sebagai berikut: 1) Pada indikator pengaturan fisik TPA FKIP UR sebesar (75\%) maka TPA FKIP UR sudah dikatakan baik. 2) Pada indikator mainan dan Peralatan TPA FKIP UR sebesar (70\%) maka TPA FKIP UR sudah dikatakan baik. 3) Pada indikator rasio pengasuh anak TPA FKIP UR sebesar (62,5\%) maka TPA FKIP UR sudah dikatakan baik. 4) Pada indikator kegiatan sehari-hari TPA FKIP UR sebesar $(100 \%)$ maka TPA FKIP UR sudah dikatakan sangat baik. 5) Pada indikator kualifikasi pengasuh TPA FKIP UR sebesar (75\%) maka TPA FKIP UR sudah dikatakan baik. 6) Pada indikator interaksi dengan orang dewasa TPA FKIP UR sebesar (83,333\%) maka TPA FKIP UR sudah dikatakan sangat baik. 7) Pada indikator hubungan dengan orang tua TPA FKIP UR sebesar (100\%) maka TPA FKIP UR sudah dikatakan sangat baik. 8) Pada indikator perizinan dan akreditasi TPA FKIP UR sebesar (75\%) maka TPA FKIP UR sudah dikatakan baik.

Sedangkan saran Berdasarkan temuan dan pembahasan hasil penelitian ini, maka terdapat beberapa rekomendasi yang dapat penulis berikan, sebagai berikut: 1) Bagi pengelola: Bagi pengelola dapat dijadikan sebagai masukkan sebagai acuan untuk menerapkan standarisasi pengelolaan. dan diharapkan kepada pengelola agar meningkatkan pengelolaan TPA FKIP UR untuk kedepannya dan dapat dijadikan TPA percontohan di Pekanbaru, 2) Bagi Dinas Pendidikan Kota Pekanbaru: Bagi dinas pendidikan dapat dijadikan masukan untuk sebagai salah satu tolak ukur untuk meningkatkan mutu pendidikan di sebuah lembaga Taman Penitipan anak dengan memberikan berbagai bantuan dan pelatihan. Bantuan dapat berupa bantuan pembangunan ruangan baru, bantuan rehab gedung lama. Pelatihan dapat berupa pelatihan pengeloalaan manajemen PAUD, pelatihan pengasuhan anak dan pelatihan tentang ilmu PAUD di sekolah, 3) Orang Tua Anak Didik: Melihat nilai yang baik dari ke delapan indikator pengelolaan TPA di TK FKIP Universitas Riau membuat orang tua anak menjadi tidak khawatir untuk memasukkan dan menitipkan anaknya untuk diasuh dan dididik di TPA FKIP Universitas Riau.

\section{DAFTAR PUSTAKA}

Anas Sudijono. 1987. Pengantar Statistik Pendidikan. Jakarta:PT.Raja Grafindo Persada

Depdiknas. 2010. Pedoman Teknik Penyelenggaraan Taman Penitipan Anak. Direktorat Pendidikan Anak Usia Dini. Jakarta.

Dini P. Daeng Sari. 1996. Metode Mengajar di Taman Kanak-kanak. Jakarta: Deparetemen Pendidikan dan Kebudayaan

Direktorat Pembinaan TK dan SD. 2007. Pedoman Pembelajaran Bidang Pengembangan Bahasa di Taman Kanak-kanak. Jakarta: Kemendiknas

Elizabeth B. Hurlock. 1993 Perkembangan Anak,Jakarta: Erlangga.

Hoerniasih, Nia. 2017. Pengelolaan Program Taman Penitipan Anak Plamboyan 3 di Kabupaten Karawang. Journal of Nonformal Education and Community Empowerment Volume 1 (1): 34-42

Kemdikbud. 2013. Petunjuk Teknis Penyelenggaraan Taman Penitipan Anak. Direktorat Pembinaan Pendidikan Anak Usia Dini. Jakarta.

Kuntjono.2010. Strategi Pembelajaran Anak Usia Dini. Jakarta

Luluk Asmawati, Dkk . 2011. Pengelolaan Kegiatan Pengembangan Anak Usia Dini. Universitas Terbuka. Jakarta.

Laura E.Berk. 2006. Child development. Library of congress Cataloging. Amerika

Nurlita. 2013. Program Pembelajaran PAUD. Pekanbaru

Nuzul F, Afrina . 2015. Pengelolaan Program Pendidikan Anak Usia Dini (Paud) Di Taman Penitipan Anak (Tpa) Dharma Wanita Persatuan (Dwp) Rumah Sakit Umum Pusat (Rsup) Dr. Sardjito Yogyakarta. Jurnal Pendidikan Luar Sekolah 
Peraturan Menteri Pendidikan Nasional, Nomor 58 Tahun 2009. Pendidikan Anak Usia Dini. Departemen pendidikan nasional. Jakarta.

Saifuddin Azwar. 2012. Penyusunan Skala Psikologi Edisi 2. Pustaka Pelajar. Yogyakarta.

Seefeldt, Carol dan Wasik Barbara A. 2008. Pendidikan Anak Usia Dini: Menyiapkan Anak Usia Tiga, Empat, dan Lima Tahun Masuk Sekolah. (Penterjemah: Pius Nasar). Jakarta: PT Indeks

Siti Aisyah dkk. 2007. Perkembangan dan Konsep Dasar Pengembangan Anak Usia Dini. Jakarta: Universitas Terbuka.

Soemardhi. 2005. Revisi: Ilmu administrasi sebagai pengantar. STKS Bandung.

Sugiono. 2008. Metode Penelitian Kuantitatif, Kualitatif. Dan R\&D. Alfabeta. Bandung.

Suyadi. 2014. Manajemen PAUD (TPA-KB-TK/RA). Pustaka Pelajar. Yogyakarta.

Zainal Aqib. 2009. Belajar dan Pembelajaran di Taman Kanak-Kanak. Bandung: Yerama Widya. 